\title{
Comparing Measures of Monocular Distance Perception: Verbal and Reaching Errors Are Not Correlated
}

\author{
Christopher C. Pagano \\ Clemson University
}

\author{
Geoffrey P. Bingham \\ Indiana University Bloomington
}

\begin{abstract}
Monocular perception of egocentric distance via optic flow generated by head movement toward a target was investigated with a helmet-mounted video camera and display. Ability to perceive target distance was assessed with 2 response measures: verbal reports and reaches. Systematic and random errors differed as a function of the response measure. Verbal estimates of targets within and beyond reach were obtained before and after the performance of reaches to targets within reach. Systematic errors of verbal estimates changed but did not decrease overall. Random error decreased. Verbal estimates and reaches were performed concurrently to targets within reach. Verbal and reaching errors were uncorrelated. Verbal judgments appear to have been anchored using the range of distances experienced while reaching rather than being calibrated to the perceptual information itself. Discussion focuses on the advantages of action response measures.
\end{abstract}

Reaching to bring the hand to a specific location in space is a usual component of everyday manual activities, such as reaching for a doorknob or a cup. The accurate execution of such activity requires information about both target distance and direction. We present research investigating the possibility that information about distance is revealed in optic flow generated by voluntary head motion. This possibility is underscored by several studies that confirm that reaching is more accurate when the head is free to move (Biguer, Donaldson, Hein, \& Jeannerod, 1988; Biguer, Prablanc, \& Jeannerod, 1984; Carnahan, 1992; Marteniuk, 1978; Prablanc, Echallier, Jeannerod, \& Komilis, 1979; Prablanc, Echallier, Komilis, \& Jeannerod, 1979).

Optic flow generated by head movement contains a radial expansion pattern in the optical elements flowing outward

Christopher C. Pagano, Department of Psychology, Clemson University; Geoffrey P. Bingham, Department of Psychology, Indiana University Bloomington.

This work was supported in part by National Science Foundation Grant BNS-9020590, by the Institute for the Study of Human Capabilities at Indiana University, and by U.S. Public Health Service Grant NRSA1FS32NS09575-01. Preliminary results were presented at the Eighth International Conference on Perception and Action, Marseille, France, July 1995. The data from some of the reaching conditions (headcam reach, occluded headcam reach, and monocular reach without headcam) were used by Bingham and Pagano (1998) for additional comparisons.

This research was conducted at Indiana University. We thank Daniel McConnell, Michael Muchisky, Jennifer Romack, and Michael Stassen for assistance in data collection and Michael Stassen for writing extensive software for data analysis. We acknowledge the following personnel from the Indiana University Psychology technical support group who helped us to design and build the headcam apparatus: Michael Bailey, William Freeman, David Link, Gary Link, and John Walkie.

Correspondence concerning this article should be addressed to Christopher C. Pagano, Department of Psychology, 418 Brackett Hall, Clemson University, Clemson, South Carolina 29634-1511. Electronic mail may be sent to cpagano@clemson.edu. from a node or focus. This focus of expansion lies in the visual solid angle projected from the surface that the point of observation would contact if translation continued in the given direction. Thus, the focus of expansion specifies the direction of heading with respect to surfaces in the surround. Humans have been found to be highly sensitive to this information and to be able to use it reliably (Warren \& Hannon, 1990; Warren, Mestre, Blackwell, \& Morris, 1991; Warren, Morris, \& Kalish, 1988). Because radial optic flow contains information about the direction of a target surface in terms of the person's heading, head movement toward a target might be an efficient way to generate information used to guide a reach. It also has been demonstrated mathematically that radial expansion generated from voluntary head movement toward a target contains information about egocentric distance (Bingham \& Stassen, 1994). We chose to investigate whether participants could use this potential information to report distance. This work is part of a larger series of studies specifically investigating the perception of egocentric distance via radial optic flow generated by voluntary head movement toward a target surface (see Bingham \& Pagano, 1998). It extends the findings of past studies regarding egocentric distance perception that have investigated motion parallax in optic flow generated by active head motion lateral to the direction of a target (e.g., Eriksson, 1974; Ferris, 1972; Foley, 1977, 1978, 1985; Foley \& Held, 1972; Gogel \& Tietz, 1979; Johansson, 1973; Rogers, 1993). In this experiment, a helmet-mounted video camera and video display was used to isolate monocular optic flow generated by the participant's own head movement toward a target. The video display produced viewing conditions similar to those used in a majority of studies involving computer graphics displays.

In this research we focused on two different response measures. Participants either judged distance verbally or reached rapidly to place a stylus in a target at eye level. The verbal judgments were made in units of the participant's arm length and thus provided a measure of perceived egocentric 
distance scaled to the participant's body. In the reaching condition, the distance at which the hand was brought up within the field of view and then moved directly toward the target along the line of sight was used as a measure of perceived distance. Because verbal judgments are not made under the same constraints present in reaching, we expected that the systematic and random errors observed with verbal judgments would differ from those observed with reaches. Specifically, greater random errors were expected with verbal judgments (see Foley, 1977, 1978, 1985; Gogel \& Tietz, 1979).

\section{A Perception-Action Approach to the Study of Definite Distance Perception}

Bingham and Pagano (1998) have argued for the necessity of a perception-action approach to the study of definite distance perception. ${ }^{1}$ The reasons derive from the fact that calibration is intrinsic to the perception of definite distance. Calibration is required because perceived distance must be scaled in the units in which it is expressed. In vision, optical information is inherently angular and must be scaled by a correlated spatial metric (e.g., velocity or distance of head movement; see Bingham \& Stassen, 1994; Koenderink \& van Doorn, 1978; Lee, 1974, 1980; Nakayama \& Loomis, 1974). These measurements must then be scaled in units used to express perceived distance-for instance, units appropriate to the control of reaching or walking or extrinsic units (e.g., foot or meter) used in verbal expression. ${ }^{2}$ Calibration is required to find the value of a coefficient used to transform measurement units to units of expression.

In distance perception studies, calibration must be studied explicitly for two related reasons. First, calibration may not succeed in eliminating systematic errors appearing in distance estimates. Both Foley $(1978)$ and Gogel $(1968,1969)$ have effectively suggested that calibration need not be studied explicitly because it can be simulated post hoc via a linear transform if a linear transform can be used to eliminate differences in systematic errors from different measures (e.g., pointing vs. verbal estimates). However, the elimination of errors via calibration is limited both by task requirements and the ability to resolve distances. Calibration depends on task-specific criteria for accuracy. Functional criteria are used to determine a tolerance inside of which estimates are accurate. Calibration adjusts measurements only to fall within such tolerance. Also, the extent to which calibration can adjust performance to fall within tolerance is limited by the level of variable errors resulting from limited visual resolution or motor error (e.g., speed-accuracy tradeoff). The amount of motor error, in turn, is partly a function of the specific action and its scale. Leg movements, for instance, are less precise than finger movements. These combined observations imply that performance in definite distance perception should be task specific.

Second, perturbations of distance perception can be properly evaluated only in the context of concurrent calibration. Stability is an issue for any measurement or action system. Calibration is bound to be required not only to achieve accuracy but also to maintain it. On the other hand, perception is investigated via perturbing it (e.g., isolating a hypothetical source of information) and determining whether the perturbation has destabilized performance (e.g., whether performance with the reduced information is comparable to that with full information). Removal of calibration is itself a perturbation. Without continuous feedback, performance may be relatively unstable and unreliable, making it difficult to evaluate the effect of any additional perceptual perturbation.

Bingham and Pagano (1998) pointed out that the ability to perceive definite distance can be assessed via targeted actions or verbal magnitude estimates but that matching can provide only a measure of relative distance perception and thus is inappropriate for the study of definite distance perception. Previous studies have shown that results from targeted action measures and from verbal estimates can be different. Targeted walking has been reliably found to be accurate (Loomis, Da Silva, Fujita, \& Fukusima, 1992; Rieser, Ashmead, Taylor, \& Youngquist, 1990; Rieser, Pick, Ashmead, \& Garing, 1995). Verbal estimates, on the other hand, have tended to underestimate actual distances but have become accurate with verbal feedback (Ferris, 1972). Nevertheless, Foley (1977) found that verbal estimates were twice as variable as estimates expressed by pointing. The question remains, What is the relation between verbal estimates and targeted action measures? We investigated this by comparing verbal estimates with performance in a reaching task.

\section{Monocular Distance Perception and Reaching}

Bingham and Pagano (1998) investigated monocular distance perception via a reaching task. Participants reached to place a stylus in a target hole and received feedback from contact with the target. In addition to normal monocular vision, Bingham and Pagano investigated the use of monocular optic flow generated by voluntary head movement toward a target. Optic flow information was isolated via a head-mounted video camera and display called the "headcam." Participants viewed disk-shaped targets in a patchlight display. The reaching task required that the hand be moved to the target as rapidly as possible but that it not hit the target surface at high speed. The distance at which the hand was brought up in front of the target was measured. The systematic errors were similar in headcam and in normal monocular viewing. Targets at increasing distance were increasingly undershot, yielding a slope less than 1 $(\approx 0.75)$ when reach distances were plotted against actual distances. Variable errors were proportional to distance in

\footnotetext{
${ }^{1}$ Definite means that the metric value of a distance is determined within measurement error. By contrast, relative means that only a ratio of a pair of distances is determined and that the metric value of any one distance in the pair is not known. See Bingham (1993b) for a discussion of the use of definite as opposed to absolute.

${ }^{2}$ Note that although distance might be expressed verbally in head movement units, for instance, such verbally expressed units are not the same as the units used to control head movements. Thus, a transformation from the control units to verbal units would be required.
} 
the normal monocular viewing condition, but not in the headcam viewing condition, in which variable errors were larger overall.

Headcam reaches tended to be somewhat shorter than normal monocular reaches. This was attributed to the restricted size of the visual field $\left(\approx 40^{\circ}\right)$ allowed by the headcam and was investigated via a control condition in which targets were viewed monocularly through a tube allowing only a $40^{\circ}$ field of view. Viewing through a tube reproduced the tendency for greater underreaching. However, when viewing was through a tube, the errors decreased over trials and approached the size and pattern of errors in normal monocular viewing. No tendency for errors to decrease over trials was found in either headcam or normal monocular viewing. In the headcam condition, this was attributed to the larger variable error, which was attributed in turn to a poorer ability to resolve distances.

The failure to correct the low slope in the normal monocular condition was similarly attributed to the pattern of variable error. However, the low slope might have been produced by a functional adaptation in the reaching task given the injunction not to hit the target at high speed. Worringham (1991, 1993), for instance, found that systematic reaching errors were proportional to variable errors in similar tasks in which the distances in question were not in depth. To investigate this possible account, Bingham and Pagano (1998) next changed the task and required participants to reach below the target to align the stylus with the target surface. Participants continued to receive feedback by placing the stylus in the target hole after having held the stylus aligned to the target. The resulting reaches overshot near targets and undershot far targets and, accordingly, continued to reflect compression of perceived distances (i.e., low slopes $\approx 0.75$ ). Low slopes could not be attributed to the need to avoid hitting the target. Finally, Bingham and Pagano compared monocular with binocular performance in the original stylus-in-a-hole task. The previous monocular results were replicated. By contrast, the binocular result was maximally accurate with slopes of one and significantly lower variable error.

The overarching conclusions were as follows: (a) Monocular vision yields compression of perceived distance that is not eliminated by calibration despite that calibration can be used to eliminate errors produced by closely related, restricted field-viewing conditions; (b) dynamic binocular vision is accurate; and (c) monocular optic flow generated by voluntary head movement toward a target, and isolated by the headcam, allows perception of distance with less resolution than normal monocular vision.

\section{Verbal Magnitude Estimation and Reaching}

In the present experiment, we compared responses made via reaching with responses made via verbal judgments. In contrast to verbal judgments, targeted reaching is a highly skilled action. Whereas many common everyday activities involve accurate targeted reaching (e.g., grasping a cup or a pen, placing a disk in a computer, hitting a switch), explicit verbal judgments of egocentric distances are extremely rare in natural situations. In contrast to verbal judgments, what constitutes accuracy in targeted reaching is relatively well defined. It is possible for both participant and experimenter to readily discern the success of any individual reach in rapidly and accurately bringing a peg to a hole. Success is inherent to the action, being related to the minimization of distance, time, and work-related variables revealed by the reach itself. The particular variable used to assess the accuracy of a given reach is determined by the nature of the task. For the task used in this experiment, accuracy was given by the distance from the location of the hand at the end of the first submovement to the location of the hand when the target hole was successfully located. Thus, the accuracy of a given reach (or, conversely, the "error") was determined solely by the manner in which that reach was executed. The determination of accuracy for a verbal judgment was much less clear and at a minimum required a judgment to be compared with an "actual distance" measured by some other means.

The main purpose of distance perception is to adjust targeted actions to the scale of the surroundings. The question is, What do verbal estimates indicate about the ability to scale other actions? For instance, if verbal estimates are found to overestimate target distances, does this mean that an individual would slam his or her hand into a target if he or she reached for it? Verbal estimates can be calibrated using verbal feedback (e.g., Ferris, 1972), but if verbal estimates are related to other actions, then they should be calibrated by those actions. We investigated verbal magnitude estimation of definite distance by examining the calibration of verbal estimates via feedback from targeted reaching.

One of the potential difficulties in relating verbal estimates to reaching is that the ranges are different. Although the range of distances within reach exhibits both a minimum and a maximum, the range of verbally estimated distances is open ended and without a maximum. Verbally, one can judge the distances to the moon. Comparison of verbal estimates to any action (e.g., targeted throwing or walking) will involve similar differences. To represent this difference between the two types of measures, we allowed the range of verbally estimated distances to remain open, although, as known to the participants, all potential distances in the study were limited by the 2-m length of the optical bench used to position the targets. By contrast, targets for reaching were kept within a participant's maximum reach distance $(\approx 50 \mathrm{~cm})$. Before a participant made an estimate or reached, he or she viewed the target monocularly via the headcam while moving his or her head toward and away from the target. Participants first performed verbal estimates without reaching or feedback. Participants then performed reaches with both headcam and normal monocular viewing, followed by another set of verbal estimates without concurrent reaching or feedback. In the next two conditions, the range of verbally judged distances was explicitly limited to fall within a participant's maximum reach distance. First, participants performed verbal estimates with concurrent reaches. This condition allowed us to examine the relation between 
verbal and reaching errors directly. However, the two tasks, simultaneously performed in this way, might have been mutually perturbing. So, after direct calibration via reaching, verbal estimates were performed once again without reaching. The focus throughout was on the relative stability and reliability of verbal versus reaching measures and the extent to which they yielded comparable results.

\section{Method}

\section{Participants}

Four participants associated with Indiana University volunteered to take part in the experiment. They ranged in age from 29 to 39 years. One participant was a woman, and the other 3 were men. All 4 were right-handed and right-eye dominant. We served as Participants 1 and 4 ; the remaining 2 participants were a graduate student and a computer programmer.

\section{Apparatus}

Figure 1 depicts the apparatus used. Participants were seated. The shoulders were strapped to the back of a chair to allow freedom of movement of the head and arm while restricting the motion of the shoulders and trunk. Participants reached with a cylindrical plastic stylus, $18.5 \mathrm{~cm}$ in length, $1.0 \mathrm{~cm}$ in diameter, and weighing $23.2 \mathrm{~g}$. The participant held the stylus firmly in the right hand, so that $4.0 \mathrm{~cm}$ extended in front and $3.2 \mathrm{~cm}$ extended behind the closed fist. Each reaching trial began with the back end of the stylus inserted in a bole in the launch platform, which was located next to the participant's hip, approximately $15 \mathrm{~cm}$ to the right, and $5 \mathrm{~cm}$ behind, the right iliac crest (the hip bone). The stylus interrupted a beam in both the launch platform and target, which triggered a signal at the beginning and end of each reach. The Cartesian coordinates of three infrared emitting diodes (IREDs) placed on a helmet, along with one IRED placed on the right index finger, were

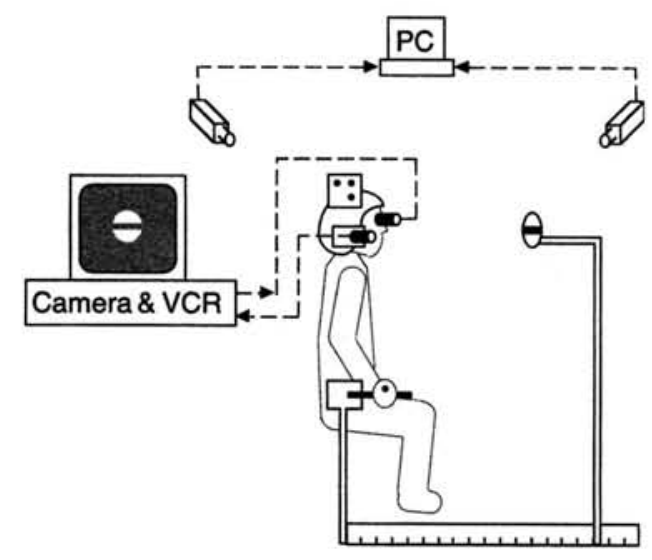

Figure 1. The apparatus used in the experiment. The participant viewed a disk-shaped target that was positioned at various distances at eye level. The target was viewed under patch-light conditions via a video lens and monitor system attached to a helmet. In the reach conditions, the participant removed a stylus from a launch pad at the hip and inserted the stylus in a hole at the center of the target. A two-camera kinematic measurement system controlled with a PC was used to measure and store the motions of an infrared emitting diode attached to the hand. sampled at $100 \mathrm{~Hz}$ with a resolution of $0.1 \mathrm{~cm}$ by a two-camera WATSMART kinematic measurement system (Northern Digital Inc., Waterloo, Ontario, Canada) and stored on a computer hard drive. A WATSCOPE connected to the WATSMART recorded the signals from the launch platform and target.

A patch was placed over the left eye. An eyepiece attached to the helmet and positioned over the right eye allowed participants to view a monochrome video display. A camera lens (the headcam) was attached to the right side of the helmet, $9.0 \mathrm{~cm}$ to the right of the eye, pointing forward. To reduce the weight of the helmet, the camera itself was placed on a nearby table and was attached to the lens by fiber-optic cable. The total weight of the helmet with viewer, lens, IREDs, and supporting hardware was $1.8 \mathrm{~kg}$. Switches allowed the experimenter to control when the head-mounted display was switched on or off. The display was switched on manually by the experimenter at the beginning of each trial and was automatically switched off at the end of each trial by a signal from the target. Thus, the display was blank between trials. Additionally, the display could be set to automatically switch off (with a delay of less than $10 \mathrm{~ms}$ ) when the stylus left the launch platform at the initiation of a reach.

The target set consisted of 18 flat, round disks covered with uniform white (i.e., smooth, textureless) retroreflective tape. Each target had a $1.2 \mathrm{~cm}$ hole at its center. A black stripe of a width corresponding to 0.25 of the target diameter was affixed across the center of the target to mask the relative size of the hole. Target size was varied so that image size varied independently of target distance. Three targets of each size could be placed at two orientations to the vertical (both orientations with the black stripe horizontal). Effectively, any of six targets could be used to produce a given image size at a given distance. Also, each target was used at more than one distance. Altogether, 78 different target configurations were used $(2$ distances $\times 2$ image sizes $\times 3$ targets $\times 2$ orientations +3 distances $\times 3$ image sizes $\times 3$ targets $\times 2$ orientations). The targets were illuminated by two fluorescent lights with parabolic reflectors mounted above and behind the participant's head. When brightly illuminated, the target appeared in the head-mounted display as an isolated shape in a dark field. The brightness and contrast of the head-mounted display were adjusted to produce patch-light images (Runeson \& Frykholm, 1981). The field was dark and structureless and continuous, with the black stripe through the center of the target. The visible target was devoid of internal texture. Before each trial one target from the set was placed at eye level at a given distance along a line extending from the camera lens, parallel to the sagittal plane of the participant. Because target size covaried with distance from the camera lens, image brightness did not vary with distance. Target position was controlled using mounts attached to an optical bench. To mask the sound of the target being positioned by the experimenter, the participant wore earphones, through which loud music was played between trials.

In summary, all binocular cues to depth were eliminated by the apparatus as well as cues that would normally be provided by texture and luminance gradients. The covariation between image size and distance was broken, so that image size could not be used reliably. The helmet-mounted display eliminated accommodation and ocular parallax (see Bingham, 1993a, 1993c) as cues to depth. The display isolated optic flow generated by voluntary head movements. Because the head movements were predominantly directed toward the target surface, and the targets consisted of uniform luminous disks against a black background, motion parallax was greatly reduced. Thus, radial outflow remained as the only source of information about depth that was not eliminated or impoverished. As an unavoidable consequence of the equipment used to provide the head-mounted display, the size of the visual 
field was restricted to about $40^{\circ}$. Investigations into the effect of this restricted field were reported by Bingham and Pagano (1998).

\section{Procedure}

In all conditions, the camera was turned off (or when there was no camera, the eye was voluntarily shut) and the headphones were turned on between trials while the experimenter adjusted the size and distance of the target. The occluding patch remained over the left eye in all conditions. Five target distances were presented in random order for each condition. A different random sampling of targets and orientations was used in each condition. Several days before the experiment, each participant sat in the apparatus with his or her shoulders strapped to the chair, and the distance of maximum reach was measured. These distances were 69.7, 65.7, 54.7, and $54.7 \mathrm{~cm}$ for Participants $1-4$, respectively. The target distances presented to the participant during the experiment are expressed as a proportion of this maximum reach. During the first two verbal judgment conditions, three target distances were within reach at $0.70,0.81$, and 0.92 of the participant's maximum reach, one was just outside the limit of reach (1.06), and one was out of reach (1.20). In all of the reaching conditions and in the final two verbal judgment conditions, target distances were all within reach at 0.50 , $0.58,0.66,0.76$, and 0.86 of the participant's maximum reach. The actual target distances in centimeters are given in Appendix A. Participants performed 25 verbal judgments, reaches, or both in each condition. Participants were allowed to remove the helmet and to rest briefly after every 12 trials.

\section{Experimental Manipulations}

Each participant was tested under seven different viewing and/or response conditions. These conditions were performed by the participants in the order that they are described (see Appendix B for a summary of the acronym structure used).

Verbal judgment before reaching (VBR). The participant viewed the target through the camera mounted on the helmet (the headcam) while actively moving his or her head toward and away from the target for $5 \mathrm{~s}$. In this time, the participant completed two to four head oscillations. After the experimenter indicated the end of $5 \mathrm{~s}$, target distances were judged without reaching. Each participant expressed distance estimates in units of his or her own arm length. Participants were instructed to assign a target at their maximum reach distance a value of 10 , one half their maximum reach a 5 , and so on. Preceding the experimental session and using normal binocular vision, each participant practiced making such judgments of the distance of the experimenter's hand, which was held in front of him or her at various distances.

Headcam reach $(R H)$. As in the previous condition, each participant looked at the target while actively moving the head toward and away from the target through two to four oscillations. The participant was instructed to reach when he or she had apprehended target distance. The participant reached to bring the hand up in front of the target and to place the front end of the stylus into the target hole as rapidly as possible, with the restriction that he or she not collide with the target at high speed.

Occluded headcam reach (ROH). The procedure was the same as that for the RH, except that the camera was automatically switched off (the participant's view became completely occluded) when the stylus was removed from the launch platform.

Monocular reach without headcam $(R M)$. The procedure was the same as that for the RH, except that participants viewed the target normally with the right eye and wore a patch over the left eye.
Verbal judgment after reaching (VAR). The procedure was the same as the first verbal judgment condition. Participants were instructed that the range of target distances might be different from those experienced in reaching conditions and should not be assumed to be the same.

Verbal judgment with feedback from reaching (VWR/RWV). The procedure was the same as the previous verbal judgment conditions, except that the participants received feedback about the accuracy of their judgments by reaching toward the target. Each participant looked at the target while actively moving the head toward and away from the target through two to four oscillations, verbally judged the target distance, and then immediately reached to place the stylus into the target hole. Thus, data concerning verbal judgments with reaching and reaching with verbal judgments were collected concurrently in the same session. The headcam was automatically switched off (the participant's view became completely occluded) when the stylus was removed from the launch platform, just as in the occluded headcam reach condition.

Verbal judgment after feedback from reaching (VAF). The procedure was the same as the previous verbal judgment conditions without reaching. The VBR and RH conditions were performed in the first session. The ROH and RM conditions were performed in a second session and the VAR condition in a third session. The VWR/RWV and VAF conditions were tested in a fourth and final session. Each session was conducted on a separate day and lasted $1.5-2 \mathrm{hr}$.

\section{Data Reduction}

The head and hand movements were recorded relative to a coordinate system with an origin at the launch platform. The $x$ direction extended horizontally away from the participant (and corresponded to the ruled markings on the optical bench dopicted in Figure 1), the $y$ direction extended horizontally to the participant's side, and the $z$ direction was vertical. The tangential velocity of the hand $(V)$, component velocities $(V x, V$, and $V z)$, distance from the target $(D)$, and component distances $(D x, D y$, and $D z)$ were computed for each sampled position along the reach trajectory. Before the velocities were computed, the positions ( $x, y$, and $z$ ) of the head- and hand-mounted IREDs were filtered by means of forward and backward passes of a second-order Butterworth filter with a resulting cutoff at $5 \mathrm{~Hz}$. (We had determined that there were no significant spectral components in the data above this cutoff.)

When the participant moved the stylus toward the target, immediately after removing it from the launch platform, there was a large vertical $(z)$ component to the hand trajectory. This was because the target was located at eye level, whereas the launch platform was located next to the hip. Participants brought the hand up into the field of view at various distances from the lens and then moved the hand horizontally along the line of sight (i.e., along the $x$ direction) to place the end of the stylus into the target hole. As shown in Figure 2, the $x$ location at which a participant raised his or her hand before turning the corner toward the target was treated as the reach distance. This locus was determined as the point at which hand velocity in the $x$ direction $(V x)$ exceeded $90 \%$ of the hand tangential velocity $(V)$. Specifically, reach distance was identified as the first point at which $V x / V \geq .90$. The reach distance was converted to arm length units by dividing by the $x$ distance of the participant's maximum reach. For our purposes, an analysis in terms of arm length units was more appropriate than one in terms of extrinsic units (e.g., centimeters, inches). We wanted to compare the reaches with verbal judgments made in intrinsic units. Additionally, the reaches were made to targets placed at distances chosen to be constant proportions of the participant's maximum reach. (See 


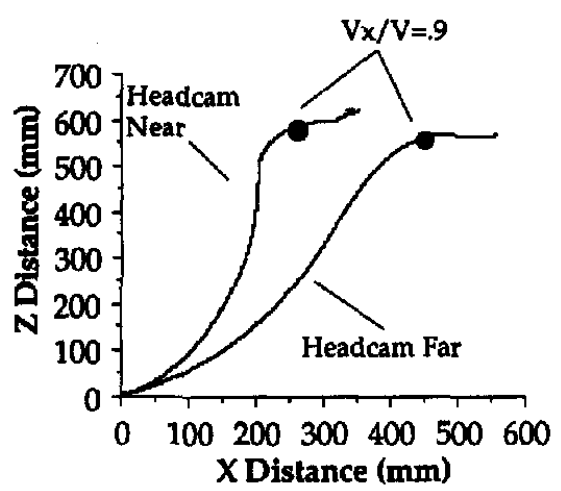

Figure 2. Mean reach paths to the nearest and farthest target projected in a vertical $x-z$ plane viewed from the right side of a participant for the headcam reach condition. The location of $V x / V=0.90$ is indicated

Bingham and Pagano, 1998, for an analysis of reach distances in terms of extrinsic units.) The degree to which the indicated target distance corresponded to the actual target distance was used as an index of accuracy in perceived target distance. Because the task required that the hand be brought up in front of the target to place the stylus in the hole, we expected that the indicated target distance in the reach conditions should underestimate the actual distance of the target by the $4.0-\mathrm{cm}$ length of the stylus beyond the hand plus a couple of centimeters for clearance.

\section{Results}

\section{Head Motions}

The mean and standard deviation values for the period and $x, y$, and $z$ amplitudes of the head movements in the headcam reach condition are presented in Table 1 for each of the participants. The amplitude values were calculated as the distance between the maximum displacements for a given trial. As can be seen from Table 1, the head movement envelopes were directed primarily in the $x$ direction, toward and away from the target surface. The amplitudes in the vertical (z) direction were small and consistent (low variability) and reflected the up-and-down excursion of the head resulting from its motions as an inverted pendulum. The side-to-side movements (those in the $y$ direction) were also

Table 1

Mean Periods and Amplitudes in the $x$

(Forward-Backward), $y$ (Side-to-Side), and $z$ (Up-Down)

Directions for the Participants in the Reaching With Vision

Through the Headcam Condition

\begin{tabular}{|c|c|c|c|c|c|c|c|c|}
\hline \multirow[b]{3}{*}{ Participant } & \multicolumn{6}{|c|}{ Amplitude (cm) } & \multirow{2}{*}{\multicolumn{2}{|c|}{ Period (s) }} \\
\hline & \multicolumn{2}{|c|}{$x$} & \multicolumn{2}{|c|}{$y$} & \multicolumn{2}{|c|}{$z$} & & \\
\hline & $M$ & $S D$ & $M$ & $S D$ & $M$ & $S D$ & $M$ & $S D$ \\
\hline 1 & 21.3 & 1.4 & 3.0 & 0.6 & 7.8 & 0.6 & 1.40 & 0.17 \\
\hline 2 & 20.5 & 1.3 & 3.9 & 0.7 & 7.8 & 0.6 & 1.83 & 0.16 \\
\hline 3 & 13.0 & 2.8 & 1.7 & 0.4 & 3.3 & 0.7 & 1.63 & 0.14 \\
\hline 4 & 14.8 & 1.2 & 2.6 & 1.0 & 4.7 & 0.4 & 1.30 & 0.10 \\
\hline
\end{tabular}

small, being about half of the vertical and one sixth of the forward-to-back movements. The $y$ amplitudes most likely reflected inevitable side-to-side excursions of the head's trajectory as it was voluntarily oscillated toward and away from the target.

\section{Systematic Errors}

We first examined systematic errors. We compared reaching and verbal performance in the first set of conditions in which the verbal and reaching ranges were different. The main question was whether reaching experience would reduce systematic errors of verbal judgments. We then examined the effect on verbal judgments of limiting the range of distances and the effect on reaches of simultaneous verbal judgment.

We performed simple regressions predicting indicated target distance from actual target distance (in arm length units) for each participant and condition. We also performed simple regressions combining the data for the 4 participants in each condition. The results are shown in Table 2. As shown in Figure 3, each of the reach conditions $(\mathrm{RH}, \mathrm{ROH}$, $R M$, and RWV) was characterized by a slope less than 1 and underestimation that increased with distance. The first verbal condition was similar (although the intercept was higher), as shown in Figure 4. The pattern of results for verbal estimates changed after the reaches were performed. The slope increased from 0.82 before reaching to 1.32 after reaching. After reaching, verbal estimates continued to underestimate target distances on average, but the steep slope reflected strong underestimation of near distances. Thus, participants judged the nearest distances as if they were the same as the nearest distances to which they had reached. Overall, the accuracy of verbal estimates was not improved.

To test differences of slopes and intercepts as a function of condition, multiple regressions were performed using actual target distance and condition (coded orthogonally) to predict indicated target distance. The regressions were first per-

Table 2

Mean Slope, $r^{2}$, Coefficient of Variation, and Overall $r^{2}$ for Combined Data in Each Viewing Condition

\begin{tabular}{|c|c|c|c|c|c|c|c|}
\hline \multirow[b]{2}{*}{ Condition } & \multicolumn{2}{|c|}{ Slope } & \multicolumn{2}{|c|}{$r^{2}$} & \multicolumn{2}{|c|}{$\mathrm{CV}$} & \multirow[b]{2}{*}{ Overall $r^{2}$} \\
\hline & $M$ & $S D$ & $M$ & $S D$ & $M$ & $\overline{S D}$ & \\
\hline VBR & 0.82 & 0.14 & .27 & .11 & .30 & .11 & .23 \\
\hline RH & 0.60 & 0.32 & .53 & .30 & .11 & .05 & .54 \\
\hline ROH & 0.60 & 0.23 & .56 & .23 & .09 & .04 & .50 \\
\hline $\mathbf{R M}$ & 0.76 & 0.08 & .86 & .06 & .06 & .04 & .83 \\
\hline VAR & 1.32 & 0.20 & .64 & .14 & .23 & .09 & .61 \\
\hline VWR & 1.06 & 0.33 & 50 & 26 & 21 & .09 & 42 \\
\hline RWV & 0.39 & 0.17 & .37 & .21 & .10 & .04 & .34 \\
\hline VAF & 1.10 & 0.34 & .60 & .25 & .19 & .10 & .50 \\
\hline
\end{tabular}

Note. $\quad \mathrm{CV}=$ coefficient of variation; $\mathrm{VBR}=$ verbal judgment before reaching; $\mathrm{RH}=$ headcam reach; $\mathrm{ROH}=$ occluded headcam reach; RM = monocular reach without headcam; VAR = verbal judgment after reaching; VWR = verbal judgment with reaching; RWV = reaching with verbal judgment; VAF = verbal judgment after feedback from reaching. 


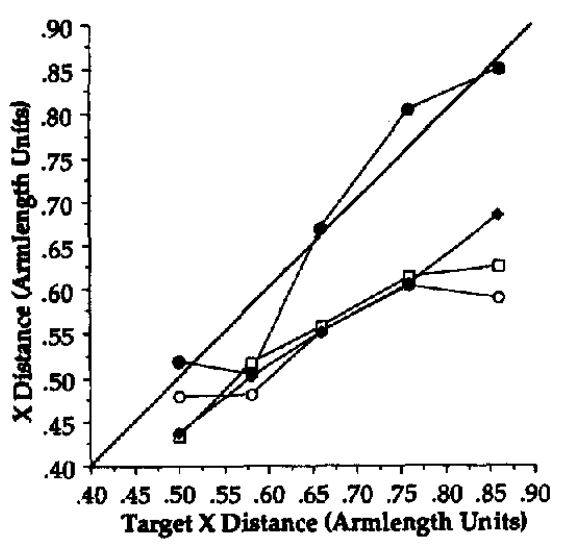

Figure 3. Mean indicated target distance as a function of actual target distance (in arm length units) for the verbal judgments made with reaches (filled circles), headcam reaches (open squares), monocular reaches (filled diamonds), and the reaches made with verbal judgments (open circles).

formed with an actual Target Distance $\times$ Condition interaction term. If the interaction was found to be nonsignificant, then it was removed and the regression was performed again without it (Pedhazur, 1982). Conditions were compared two at a time. The results are presented in Table 3. In a multiple regression comparing the headcam reaches and the monocular reaches, the interaction term was not significant, indicating that the slopes of these two conditions did not differ. When the interaction term was removed from the model, a significant effect for condition was found. On average, the headcam reaches were $1.2 \mathrm{~cm}$ farther from the target than the monocular reaches without headcam. Bingham and Pagano (1998) showed that this effect was produced by the restricted size of the visual field in the headcam. The relative underestimation effect was replicated by having participants view targets through a tube that similarly restricted the size

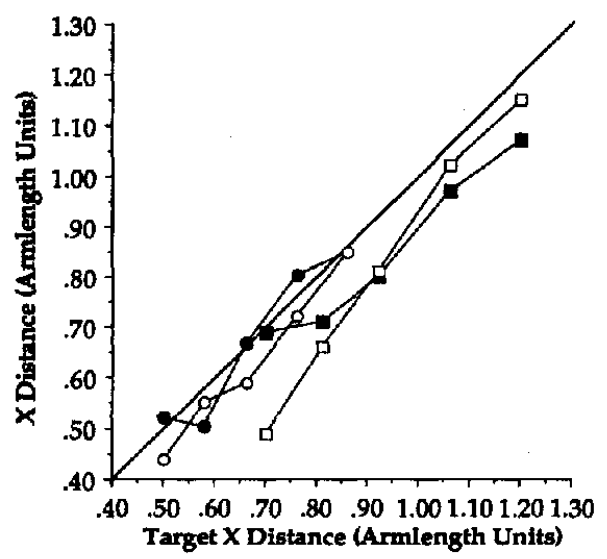

Figure 4. Mean indicated target distance as a function of actual target distance (in arm length units) for each of the verbal conditions: verbal before reaching (filled squares), verbal after reaching (open squares), verbal with reaching (filled circles), and verbal without feedback (open circles).
Table 3

Values of $r^{2}$ and Partial F for Multiple Regressions

Predicting Indicated Target Distance From Actual Target Distance (in Arm Length Units), Condition, and the Target Distance $\times$ Condition Interaction Using Participants' Combined Data

\begin{tabular}{|c|c|c|c|c|}
\hline \multirow{2}{*}{$\begin{array}{l}\text { Viewing } \\
\text { conditions } \\
\text { compared }\end{array}$} & \multirow[b]{2}{*}{$r^{2}$} & \multicolumn{3}{|c|}{ Partial $F$} \\
\hline & & $\begin{array}{c}\text { Target } \\
\text { distance }\end{array}$ & Condition & Interaction \\
\hline RH vs. RM & $\begin{array}{l}.66 \\
.66\end{array}$ & $\begin{array}{l}361.4 * * * \\
359.7 * * *\end{array}$ & $\begin{array}{l}<1 \\
13.9 * *\end{array}$ & 1.23 \\
\hline $\begin{array}{l}\text { VBR vs. VAR } \\
\text { VAR vs. VWR }\end{array}$ & $\begin{array}{l}.42 \\
.59 \\
.58\end{array}$ & $\begin{array}{l}135.7^{* * *} \\
197.7^{* * *} \\
235.1^{* * *}\end{array}$ & $\begin{array}{c}7.9^{* *} \\
7.6^{* *} \\
27.3^{* * *}\end{array}$ & $\begin{array}{l}7.5^{* *} \\
2.3\end{array}$ \\
\hline $\begin{array}{l}\text { VWR vs. RWV } \\
\text { RH vs. RWV } \\
\text { VWR vs. VAF }\end{array}$ & $\begin{array}{l}.49 \\
.45 \\
.46 \\
.46\end{array}$ & $\begin{array}{l}115.3^{* * * *} \\
153.6^{* * *} \\
165.9 * * * \\
166.7^{* * *}\end{array}$ & $\begin{aligned} & 8.9^{*} \\
& 6.0^{*} \\
&<1 \\
& 3.6\end{aligned}$ & $\begin{array}{l}17.7^{* * * *} \\
6.1^{*} \\
<1\end{array}$ \\
\hline
\end{tabular}

Note. $\mathrm{RH}=$ headcam reach; $\mathrm{RM}=$ monocular reach without headcam; VBR = verbal judgment before reaching; VAR = verbal judgment after reaching; VWR = verbal judgment with reaching; RWV = reaching with verbal judgment; VAF = verbal judgment after feedback from reaching.

${ }^{*} p<.05$. ${ }^{* *} p<.01$. $\quad{ }^{* * *} p<.001$.

of the monocular field. This effect aside, systematic errors were similar with and without the headcam apparatus. A multiple regression comparing verbal judgments made before reaching to those made after reaching showed that changes in both slope and intercept were significant. Thus, the pattern of systematic error in verbal judgments was altered by the intervening reach conditions, although verbal judgments as a whole did not become more accurate.

Judgments were again altered when accompanied by reaches, a condition in which the range of possible distances was explicitly restricted. When verbal judgments made after reaching were compared with those performed with reaches, the interaction was not significant, but the change in intercept was. Neither the interaction nor the main effect was significant in a multiple regression comparing verbal judgments with reaching and verbal judgments after feedback.

A multiple regression comparing the reaches made with verbal judgments and the corresponding verbal judgments showed that both slopes and intercepts were significantly different. As shown in Table 2, the slopes for verbal judgments with reaching were close to 1 , whereas those for reaching with verbal judgment were less than 1 (as for all reaches). An additional multiple regression comparing headcam reach and reaching with verbal judgment also yielded significant effects for both slope and intercept. This latter result indicated that reaching was perturbed by the accompanying verbal judgments. As shown in Table 2, the reaching with verbal judgment condition was characterized by a lower slope. The reaches were less accurate when immediately preceded by verbal judgments.

In summary, regression analyses yielded three main findings: First, verbal judgments were changed by intervening reaches but did not become more accurate. Verbal judgments before reaching were characterized by slopes less 
than 1, whereas after reaching, the slopes were greater than 1. Second, limiting the range of verbal judgments to that of concurrent reaches reduced systematic error in verbal judgments. The slopes in the verbal judgment with reaching and the verbal judgment after feedback conditions were near 1 , and mean judgments were maximally accurate. Third, the reaches were perturbed by immediately preceding verbal judgments but were otherwise stable across the monocular and headcam viewing conditions. Slopes near 0.70 in the latter conditions dropped to 0.40 in the former.

\section{Variable Errors}

Next, we examined variable errors. We compared the variability of reaches and verbal estimates. The question was whether reaching experience might reduce variable errors of verbal estimates to the level of reaches. We found that the variability of verbal estimates was reduced by reaching experience but that the variability was less in all of the reach conditions than in any of the verbal conditions. Overall, the mean coefficients of variation were $.30, .23, .21$, and .19 for the VBR, VAR, VWR, and VAF conditions, respectively, and $.11, .09, .06$, and .10 for the $\mathrm{RH}, \mathrm{ROH}, \mathrm{RM}$, and RWV conditions, respectively (i.e., the means of the coefficients of variation computed at each of five target distances for each of the 4 participants). To determine whether the coefficients of variation differed as a function of response measure, we performed a $6 \times 5$ repeated measures analysis of variance with the within-subjects factors of condition and target distance. We included the six conditions that involved similar target distances: RH, ROH, RM, RWV, VWR, and VAF. Condition was significant, $F(4,12)=7.9, p<.001$, but target distance and the interaction were not. In simple effects tests, condition was significant at all distances except the largest $(p<.05)$, whereas distance was not significant in any condition. In $t$ tests of pairwise comparisons, the coefficients of variation for the verbal judgment with reaching and the verbal judgment after feedback conditions were greater than for each of the reach conditions $(p<.05)$ but not from one another, and no other differences were significant. Thus, even after concurrent reaching, verbal estimates were significantly less precise than reaches.

To evaluate potential changes in errors over trials, we subtracted estimated target distances (in arm length units) from the actual target distances and then took the absolute values. Simple regressions predicting these errors from trial number resulted in nonsignificant $r^{2}$ values for all 4 participants in each of the seven conditions except in verbal judgment before reaching. In this condition, this simple regression was significant for Participants 2 and $3\left(r^{2} \mathrm{~s}=.17\right.$ and .20 , respectively, $p s<.05 ; n=25$ ) but with a positive slope for both, indicating an increase in overall error with continued performance. None of the regressions was significant when performed with signed errors. Thus, verbal errors in particular did not improve over successive trials as a result of feedback from reaching.

Finally, reaching errors were compared directly with verbal errors. Signed reaching and verbal errors were plotted against trial for each participant in Figure 5, where mean errors computed for each trial are also shown. The verbal judgment with reaching errors were regressed on the reaching with verbal judgment errors for corresponding trials to evaluate whether reaching error was related to the error in the preceding verbal judgment within a trial. These regressions were not significant for Participants $1-3\left(r^{2} s=0, .10\right.$, and .09 , respectively). For Participant 4 , the regression was significant $\left(r^{2}=.32, p<.01\right)$, however; when the data for two trials ( 2 and 4 ) were removed, the $r^{2}$ dropped to .13 and the result was no longer significant. To test the possibility that the first few trials were required to enable verbal and reaching errors to become related, we performed these regressions again using only the data from Trials 12-13. None of the results was significant. To test whether reaching error might be related to the verbal error of the following trial, we regressed reaching errors on verbal errors from the following trials (i.e., Lag 1), but, again, none of the results was significant. As shown in Figure 5, the errors appeared to oscillate. The overall finding was that reaching errors were independent of verbal errors. As shown in Figure 5, verbal and reaching errors may possibly have tracked one another briefly during the middle of the experimental session but then diverged. This was most likely the case for Participant 4. We interpreted this to mean that it is possible for reaches and verbal estimates to track one another but that this strategy was not optimal.

In summary, analyses of variable error produced four main findings: First, the variability of verbal estimates was consistently higher than the variability of reaches. This was the case even when and after reaches and verbal judgments were performed concurrently. Second, although the variability of verbal estimates showed improvement over the course of the experiment, the variability of reaches remained constant. The fact that the variability in the verbal judgment with reaching and the verbal judgment after feedback conditions did not differ suggested that the decline in variability for verbal judgments had leveled out by the end of the experiment. The variability in the final verbal condition remained higher than that observed in the first, and all subsequent, reaching conditions. Third, the analysis of error as a function of trial revealed no significant improvement in performance over trials within any condition. In particular, errors in verbal judgments did not decline in the VWR condition, where feedback from reaching was available concurrently. Fourth, error associated with reaches made immediately after verbal judgments was not related to the error in those verbal judgments. Also, reaching error was not related to verbal error in the following trial. The trends in verbal and reaching responses were not related directly.

\section{Discussion}

We compared verbal estimates and reaches as measures of perceived egocentric distance of a target. We found that verbal estimates of distance were relatively unstable and unreliable. Their instability was revealed by dramatic changes in the pattern of systematic errors between experimental conditions (as compared with the relatively stable pattern of reaching errors) and by variable errors that were at least 

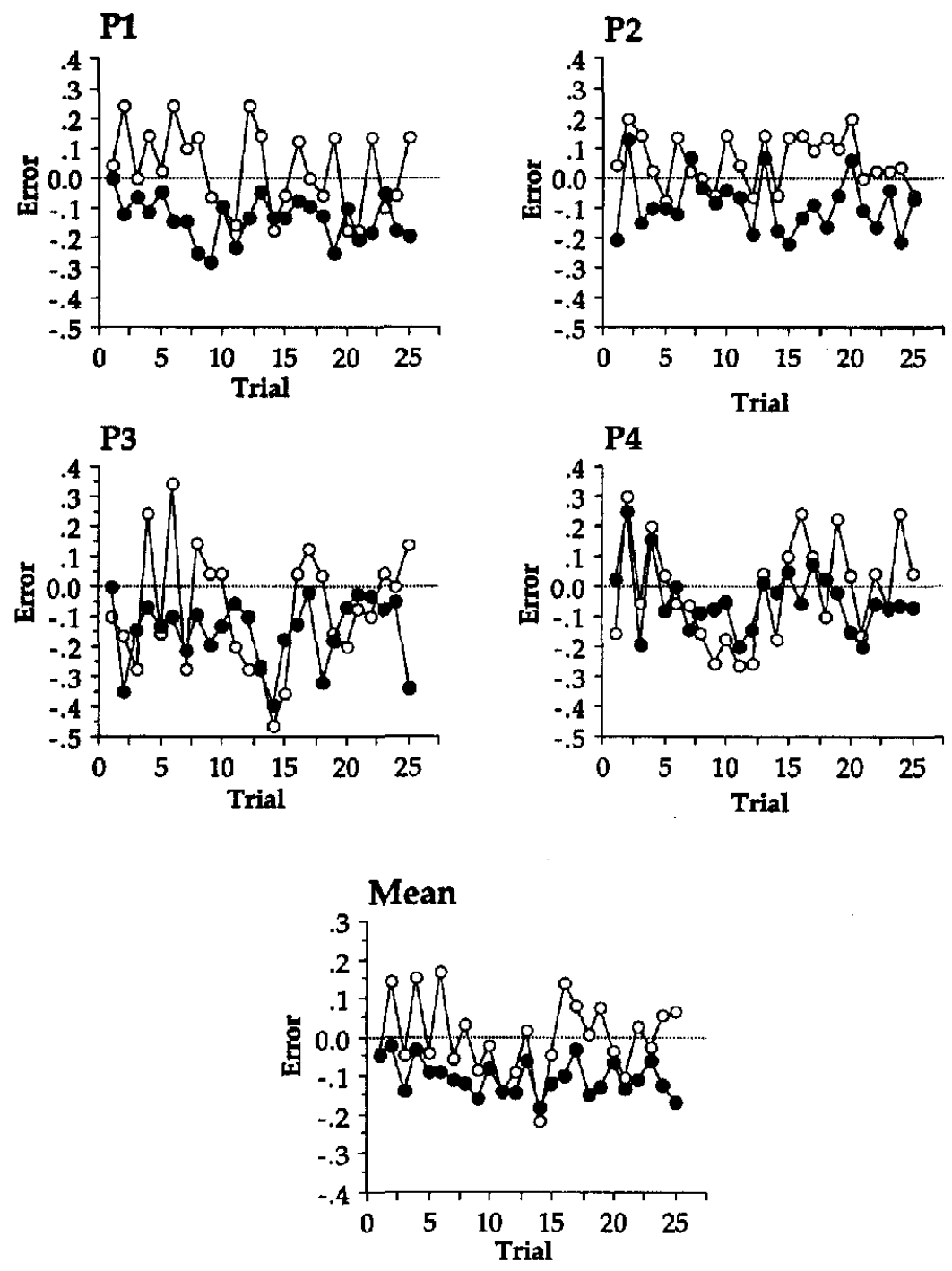

Figure 5. Errors as a function of trial number for each of the 4 participants (P1 through P4), together with means computed across participants. Shown are verbal judgments made with reaches (open circles) and reaches made with verbal judgments (filled circles).

twice as large as those for reaches. The variable error of verbal estimates might be expected to be larger than that of reaches because, whereas reaches can vary continuously with target distances, verbal estimates are limited, by participants' use of numbers, to the 20th part of the unit of measure (Poulton, 1989). (Judgments in arm length units were typically expressed using numbers such as $0.5,0.55$, $0.6,0.65$, etc.) Nevertheless, without the feedback and range limitations of reaching, we found the variability of verbal estimates to be three to five times greater than that for reaches.

The unreliability revealed by the changes in systematic errors was more significant. Most troubling, in this respect, was that in the final two conditions the slopes for verbal judgments were approximately equal to 1 . Bingham and Pagano (1998) tested reaches with monocular vision in several viewing conditions and experiments and reliably found slopes less than $1(\approx 0.75)$. This was also true both for reaches to place the stylus in the target hole and for reaches under the target to align the stylus with the surface. However, when Bingham and Pagano tested binocular vision, they obtained slopes of 1 ! The collective results demonstrated that low slopes could be attributed to monocular distance perception (as opposed to binocular), not to the reaching as such. Therefore, the fact that slopes near 1 were obtained in the current study with monocular vision implies that verbal judgments do not provide a reliable measure of visual abilities.

We investigated the relation between verbal estimates and a targeted action by testing whether feedback from reaching could be used to calibrate verbal estimates. In the first two verbal conditions before and after reaching, we manipulated feedback from reaching without introducing the range limitations of reachable distances. The result was that 
reaching experience affected verbal judgments (i.e., the slope became steeper and the variability lessened). However, mean verbal estimates did not become more accurate or more closely aligned to mean reaches. Despite participants having been told that the range of distances might be different, they apparently calibrated their judgments by anchoring the nearest targets at the nearest distance experienced when reaching. Thus, participants appear to have used the reaching to calibrate the range of distances rather than the information about distance as such. The reduction in variability might similarly be attributed to reliable use of the particular range.

In the final two verbal conditions, the range of distances for reaches and verbal estimates were necessarily identical. Given the results in the first two verbal conditions, we inferred that participants in these final conditions correctly anchored the range for judgments to the nearest and farthest reaching distances. This inference was supported by analyses of the pattern of errors over trials. First, errors were not found to decrease over trials in any condition including that with concurrent reaching and verbal estimates. (Bingham \& Pagano, 1998, found that feedback from reaching could be used to reduce reaching errors produced by monocular viewing with a restricted visual field.) This implied that feedback from reaching was not being used to calibrate verbal estimates progressively. To the contrary, verbal estimation was found to perturb reaching, hindering the ability to perform accurate reaches. Second, no direct relation was found between reaching and verbal errors when the two were performed concurrently. Although the random variability of both reaches and verbal estimates decreased over trials, the noisy oscillatory processes exhibited in each instance were uncorrelated. Thus, the surprising conclusion to be drawn from these studies is that feedback from reaching is not used to calibrate verbal estimates of perceived distance beyond crude presumptive calibration of the range of distances.

How should we understand this apparent dissociation between reaching and verbal estimates as expressions of perceived distance? That there might be two separate, perhaps competing, systems is supported by the fact that one seems to perturb the other and by the following anecdotal evidence of a "Dr. Strangelove effect." Our participants expressed surprise on some trials. In debriefing, they reported that they had (verbally) judged the target to be at one distance and "had told their hand to go there, but it went elsewhere and it was right!" On the other hand, the evidence from Participant 4, in particular, seems to show that one can reach to verbally expressed distances but that doing so is not the best way to perform the combined tasks. We review and evaluate two accounts for the dissociation.

\section{Task Specificity of Perception-Action}

Targeted walking has also been used to study distance perception. In this instance, accurate performance has been observed in numerous studies in which participants first viewed a target with normal binocular vision and then walked blindly to the target (Loomis et al., 1992; Rieser et al., 1990, 1995). Rieser et al. (1995) investigated both targeted walking and targeted throwing and showed that each action could be recalibrated without affecting the other. In their experiments, participants first performed targeted walking accurately. Participants then walked on a treadmill while the treadmill was pulled on a cart around a parking lot. The cart was pulled at speeds faster (or slower) than the treadmill speed. In this way, participants were exposed to optic flows that were faster (or slower) than appropriate to their walking. When the participants subsequently performed the targeted walking task again, they under- or overshot the target distances. When participants were asked to throw beanbags to the targets, however, their performance was unaffected and remained accurate. Participants then rode on the cart and threw beanbags to approaching (or retreating) targets until they could hit the targets reliably. Standing again on the ground, participants under- or overshot the targets with the beanbags but targeted walking remained unaffected. Rieser et al. (1995) argued that this ability to recalibrate walking and throwing independently shows that human behavior is composed of a collection of relatively independent perception-action systems.

In the past decade, several researchers have suggested that human actions be approached as task-specific devices (e.g., Bingham, 1988; Kugler \& Turvey, 1987; Saltzman \& Kelso, 1987; Solomon, 1988; Solomon \& Turvey, 1988; Turvey \& Carello, 1995). The basic notion is that dynamical properties of the muscles, bones, and other anatomical structures are harnessed to produce deterministic dynamics used to perform specific tasks. For instance, walking is achieved by organizing the legs to function as a combination of upright and inverted pendulums (McMahon, 1984), whereas throwing is accomplished via a combination of a mass-spring and whiplike dynamics (Bingham, Schmidt, \& Rosenblum, 1989). ${ }^{3}$ The problem in this approach is to control the device to accomplish the assigned task. Given the difference in dynamics, controlling a throwing device is much different from controlling a walker. Distance would map to the kinetic energy and angle of release in the former and to the number of cycles of oscillation in the latter. The control variables to be calibrated would be different in each instance. When actions are viewed in this way, the possibility that calibration might not transfer between types of responses would be expected.

In particular, in the case of reaching and verbal estimates, the relation between the parameters used to control reaching and any set of numbers used to express perceived distances verbally cannot be simple. One can reach to the same positions at eye level in the sagittal plane with an empty hand or with a hand holding a shotput or with a hand straining against a spring attached to a wall behind the shoulder, and the reaching parameters must be different in each instance and the verbally expressed numbers will be the same. Reaches occur in a space that is highly structured and

\footnotetext{
${ }^{3}$ For a similar approach to robotics, see Beer (1990) and, in particular, Raibert (1982), who designed a finite state machine to control the mass-spring and projectile motion dynamics of a hopper and thus produced a stable, flexible runner.
} 
constrained. Not only is the workspace bounded, but it has been demonstrated that different limb configurations in the workspace are characterized by different postural stiffness and inertial ellipses (Flash \& Mussa-Ivaldi, 1990; Hogan, 1985, 1990; Mussa-Ivaldi, Hogan, \& Bizzi, 1985). The shape and orientation of these ellipses vary systematically throughout the workspace while remaining invariant over participants, time, and forces produced to counter mechanical disturbances. Thus, these ellipses are informative about the space in which an action is currently unfolding. In other words, the limb's workspace is structured, or "textured," by the dynamics of the limb, and thus obtained stimulation is similarly structured (see Pagano \& Turvey, 1995; Riccio, 1993). Consequently, the stimulation generated by one's performance is informative about the limb's configuration within the workspace. Recently, Kay, Hogan, Mussa-Ivaldi, and Fasse (1989) found that the haptic perception of object lengths and surface stiffnesses varied over the workspace in a way that was similar to the variation in postural dynamics. These results imply that the control parameters for reaching will vary with distance in different ways in different directions. Calibration of perceived reaching distance in terms of these anisotropic parameters would be distinct from calibration in terms of isotropic measures expressed verbally.

An important aspect of task-specific devices is their soft assembly. A soft system is temporarily assembled from general dynamic properties, not specific anatomical components, to fit current task constraints (Bingham, 1988; Kugler \& Turvey, 1987; see also Carello, Fitzpatrick, Domaniewicz, Chan, \& Turvey, 1992; Pagano, Fitzpatrick, \& Turvey, 1993). The soft assembly of perception-action systems for the purpose of executing functionally similar actions involves the harnessing of similar dynamic constraints. With visual targets, for example, reaching to the forward face of a target in near space versus reaching underneath the target involves dynamics that are of like kind (Bingham \& Pagano, 1998), as does walking forward or sideways to a more distant target location. The constraints are altered substantially, however, if the task is changed to one involving a different action, such as throwing (Rieser et al., 1995). Likewise, the soft assembly of a task-specific device for the haptic exploration of an object involves the harnessing of similar dynamics when the assembly is made over varying anatomical components (e.g., Carello et al., 1992; Pagano et al., 1993; see also Turvey \& Carello, 1995). These biomechanic constraints are perceptually available to the actor because they are harnessed in the performance of the task and may provide a basis for the calibration of perceptionaction systems. By contrast, the nature of constraints under which verbal judgments are made is unclear. Our work indicates that these action-related (e.g., biomechanical) constraints lend manual responses a stability that is not present in the less constrained verbal responses.

\section{Separate "What" and "How" Visual Systems}

Goodale and Milner (1992; Goodale, 1988, 1995; Milner \& Goodale, 1993, 1995) have hypothesized that two anatomically distinct visual systems exist, one underlying conscious perception and one underlying the visual control of action. They hypothesized that the projection to the temporal lobe (the ventral stream) furnishes conscious perceptual experience, whereas the parietal cortex (the dorsal stream) provides action-related information about the visual scene. They used the term perception to refer to output from the anatomical system responsible for the conscious perception and memory of persistent surface properties such as color, texture, and shading as well as some aspects of layout and distance. They used the term action to refer to output from the visual system responsible for the guidance of actions. It seems likely that the system supporting conscious perceptual experience of the visual world evolved much more recently than that which supports controlled actions within it and that the two systems are to some degree separate (Goodale, 1988, 1995; Milner \& Goodale, 1995). As Goodale (1995) noted,

natural selection has little to do with how well an animal sees the world; it operates at the level of the overt behavior that enables the organism to avoid predators, find mates, forage for food, and move from one part of the environment to another. (p. 173)

Goodale and Milner (1992) also referred to this distinction as one between "what" and "how" visual systems and viewed it as a revision of the "what" and "where" distinction that had been previously proposed by others (e.g., Schneider, 1969; Trevarthen, 1968; Ungerleider \& Mishkin, 1982). "What" and "where" distinguished the perception of object qualities and identification versus the perception of object location. By contrast, "what" and "how" distinguishes different response requirements met by two separate systems (e.g., verbal report vs. action) and thus better captures the functional dichotomy between these different anatomical systems (Goodale, 1988; Goodale \& Milner, 1992; Milner \& Goodale, 1993). The "what" versus "how" distinction is also more relevant to the possibility that actions as complex as locomotion are guided by portions of the visual system separate from those underlying conscious visual perception (Loomis et al., 1992; Turvey, 1977; see also Proffitt, Bhalla, Gossweiler, \& Midgett, 1995). It seems that "where" questions can be asked of either system.

Several cases have been reported in which individuals have received damage to one of these visual systems while the other remained spared (Goodale \& Milner, 1992; Goodale, Milner, Jakobson, \& Carey, 1991; Milner \& Goodale, 1993). One such patient (D.F.) was unable to consciously recognize the size, shape, or orientation of visual objects but was able to accurately reach to such objects. When asked to explicitly report size or orientation, for example, the patient's performance did not differ from chance. When asked to reach, however, the patient was able to accurately scale her grip to the size of an object or orient her hand to match that of a target. ${ }^{4}$ Note that the Patient D.F. performed differently

\footnotetext{
${ }^{4}$ A similar division has been observed in the tactile modality (e.g., Paillard, Michel, \& Stelmach, 1983; Rossetti, Rode, \& Boisson, 1995).
} 
depending on the type of manual responses she was asked to perform. She was unable to indicate the width of an object using the thumb and index finger or to indicate the orientation of a target either verbally or by rotating the hand. By contrast, she was as good as normal participants when asked to reach. The manual responses revealing an ability to perform can be distinguished from manual responses revealing an inability to perform by the degree to which they were associated with either action-related or analytical (conscious) processes. Such manual processes have also been referred to as "motor" and "cognitive," respectively (Bridgeman, 1989).

Relatedly, there are circumstances in which normal participants are unaware of changes in the visual array to which their motor system is expertly adjusting. Examples are provided by research demonstrating participants' ability to accurately reach or point to targets displaced during or near saccadic eye movements while being unable to consciously detect such displacements (Bridgeman, Kirch, \& Sperling, 1981; Bridgeman, Lewis, Heit, \& Nagle, 1979; Goodale, Pélisson, \& Prablanc, 1986; Pélisson, Prablanc, Goodale, \& Jeannerod, 1986). Participants have also been shown to adjust their posture according to small changes in optic flow while not being consciously aware of either the postural adjustments or the variations in optic flow (Lee \& Lishman, 1975)..$^{5}$ Similarly, the motor system may respond accurately toward actual target positions when viewing conditions are such that consciously perceived target locations contain illusory displacements. This has been demonstrated in pointing tasks (Bridgeman, 1993; Bridgeman et al., 1981), a task requiring participants to strike a target with a hammer (Hansen, 1979; Hansen \& Skavenski, 1977), and with saccadic eye movements (Wong \& Mack, 1981; see also Mack, Fendrich, \& Pleune, 1978). Bridgeman et al. (1981) noted that

when the cognitive system is subject to illusions of induced motion, ... contradictory and more accurate spatial information is retained in a separate map of visual space, a map that is used by the motor system to guide behavior but is not normally accessible to experience. (p. 341)

It is possible that this distinction, along with the concept of task-specific devices, is responsible for the differences between verbal and manual results observed in our work. It seems that the portion of the visual system that is harnessed in the assembly of a task-specific device for an action system is separate from that which is harnessed for the assembly of a device geared toward verbal or analytical (conscious) responses. Although research has demonstrated similarities in perception via assemblies over varying anatomical components (e.g., Barac-Cikoja \& Turvey, 1993; Carello et al., 1992; Pagano et al., 1993), it remains obvious that separate anatomical components are often differentially suited for the performance of a given task. The anatomical structures associated with the legs and feet, for example, are much better suited for providing locomotion than the arms and hands, whereas the latter are better suited for grasping and manipulating objects. One can learn to walk on one's hands or to pick up objects with the feet, but these are clearly not the primary functions for which these structures evolved. Similarly, different exploratory procedures are used in the haptic perception of distinct object properties, such that different anatomical components are optimally used to extract cutaneous, kinesthetic, or thermal parameters (Lederman \& Klatzky, 1987, 1990). Although the theorizing on task-specific devices has primarily focused on soft assembly over anatomical structures involving muscle and bone, we claim that the theory should be extended to include differences in neural structures. On the basis of the evidence of separate visual streams, one should expect these separate neural systems to be harnessed for different types of visual tasks. A task requiring a verbal response or the conscious report of a magnitude through a matching procedure will involve the harnessing of the ventral system, whereas a task requiring a rapid reach or other continuous action will involve the harnessing of the dorsal system. Importantly, a perceptual system that is assembled out of components more intimately tied to the action system (the dorsal stream, or "how" system) will be more sensitive to the constraints within which the action system must perform. These constraints provide intrinsic structure and scale to the system's output as well as provide intrinsic structure and scale for the system's calibration.

So, what might verbal estimates of perceived distance indicate about one's ability to reach accurately to a distance? We claim that it does not indicate much. In the end, we found that verbal estimates were imprecise but, after calibration, on average close to the mark. By contrast, reaching was less close on average, but much more precise. In addition, reaching was fairly accurate. Participants usually got the stylus in the hole. In comparison, because the criteria for accuracy are ambiguous, it is not clear whether one should call the verbal estimates accurate. More to the point, given the level of imprecision, the average level of verbal performance was less representative of verbal estimates than the average level of reaching was of reaching. Finally, over the course of calibration and changes in the range of possible distances, the pattern of verbal errors changed significantly. In view of all this, the best way to evaluate the ability to perceive distance for reaching is to observe reaching itself.

\footnotetext{
5 These changes in the visual array are occurring at a small scale. With the moving room example, when the amplitude of motion becomes large enough, ankle motion is detected kinesthetically and reported (Lee \& Lishman, 1975). Thus, there is a scale at which the action system is monitoring behavior and the relation to the surroundings and handling small fluctuations without conscious awareness. It could be argued that people would not want to be conscious of innumerable small-scale fluctuations.
}

\section{References}

Barac-Cikoja, D., \& Turvey, M. T. (1993). Haptically perceiving size at a distance. Journal of Experimental Psychology: General, 122, 347-370.

Beer, R. D. (1990). Intelligence as adaptive behavior: An experiment in computational neuroethology. San Diego, CA: Academic Press. 
Biguer, B., Donaldson, I. M. L., Hein, A., \& Jeannerod, M. (1988). Vibration of the nape of the neck muscles modifies the perceived location of a visual target. Brain, 303, 43-48.

Biguer, B., Prablanc, C., \& Jeannerod, M. (1984). The contribution of coordinated eye and head movements in hand pointing accuracy. Experimental Brain Research, 55, 462-469.

Bingham, G. P. (1988). Task-specific dynamics and the perceptual bottleneck. Human Movement Science, 7, 225-264.

Bingham, G. P. (1993a). Optical flow from eye movement with head immobilized: "Ocular occlusion" beyond the nose. Vision Research, 33, 777-789.

Bingham, G. P. (1993b). Perceiving the size of trees: Form as information about scale. Joumal of Experimental Psychology: Human Perception and Performance, 19, 1139-1161.

Bingham, G. P. (1993c). Scaling judgments of lifted weight: Lifter size and the role of the standard. Ecological Psychology, 5, $31-64$.

Bingham, G. P., \& Pagano, C. C. (1998). The necessity of a perception-action approach to definite distance perception: Monocular distance perception for reaching. Journal of Experimental Psychology: Human Perception and Performance, 24, 145-168.

Bingham, G. P., Schmidt, R. C., \& Rosenblum, L. D. (1989). Hefting for a maximum distance throw: A smart perceptual mechanism. Joumal of Experimental Psychology: Human Perception and Performance, 15, 507-528.

Bingham, G. P., \& Stassen, M. G. (1994). Monocular distance information in optic flow from head movement. Ecological Psychology, 6, 219-238.

Bridgeman, B. (1989). Complementary cognitive and motor image processing. In G. Obrecht \& L. W. Stark (Eds.), Presbyopia research: From molecular biology to visual adaptation (pp. 189-198). New York: Plenum.

Bridgeman, B. (1993). Separate visual representations for perception and for visually guided behavior. In S. R. Ellis, M. Kaiser, \& A. J. Grunwald (Eds.), Pictorial communication in virtual and real environments (2nd ed., pp. 316-327). Washington, DC: Taylor \& Francis.

Bridgeman, B., Kirch, M., \& Sperling, A. (1981). Segregation of cognitive and motor aspects of visual function using induced motion. Perception \& Psychophysics, 29, 336-342.

Bridgeman, B., Lewis, S., Heit, G., \& Nagle, M. (1979). Relation between cognitive and motor-oriented systems of visual position perception. Journal of Experimental Psychology: Human Perception and Performance, 5, 692-700.

Carello, C., Fitzpatrick, P., Domaniewicz, I., Chan, T. C., \& Turvey, M. T. (1992). Effortful touch with minimal movement. Journal of Experimental Psychology: Human Perception and Performance, 18, 290-302.

Carnahan, H. (1992). Eye, head and hand coordination during manual aiming. In L. Proteau \& D. Elliot (Eds.), Vision and motor control (pp. 179-196). Amsterdam: Elsevier.

Eriksson, E. S. (1974). Motion parallax during locomotion. Perception \& Psychophysics, 16, 197-200.

Ferris, S. H. (1972). Motion parallax and absolute distance. Joumal of Experimental Psychology, 95, 258-263.

Flash, T., \& Mussa-Ivaldi, F. (1990). Human arm stiffness characteristics during the maintenance of posture. Experimental Brain Research, 82, 315-326.

Foley, J. M. (1977). Effect of distance information and range on two indices of visually perceived distance. Perception, 6, $449-460$.

Foley, J. M. (1978). Primary distance perception. In R. Held, H. W. Leibowitz, \& H. L. Teuber (Eds.), Handbook of sensory physiology, Vol. 8. Perception (pp. 181-213). Berlin: Springer-Verlag.
Foley, J. M. (1985). Binocular distance perception: Egocentric distance tasks. Journal of Experimental Psychology: Human Perception and Performance, 1I, 133-149.

Foley, J. M., \& Held, R. (1972). Visually directed pointing as a function of target distance, direction, and available cues. Perception \& Psychophysics, 12, 263-268.

Gogel, W. C. (1968). The measurement of perceived size and distance. In W. D. Neff (Ed.), Contributions to sensory physiology (Vol. 3, pp. 125-148). New York: Academic Press.

Gogel, W. C. (1969). The sensing of retinal size. Vision Research, 9, 3-24.

Gogel, W. C., \& Tietz, J. D. (1979). A comparison of oculomotor and motion parallax cues of egocentric distance. Vision Research, 19, 1161-1170.

Goodale, M. A. (1988). Modularity in visuomotor control: From input to output. In Z. Pylyshyn (Ed.), Computational processes in human vision: An interdisciplinary perspective (pp. 262-285). Norwood, NJ: Ablex.

Goodale, M. A. (1995). The cortical organization of visual perception and visuomotor control. In S. M. Kosslyn \& D. N. Osherson (Eds.), Visual cognition: An invitation to cognitive science (pp. . 167-213). Cambridge, MA: MTT Press.

Goodale, M. A., \& Milner, A. D. (1992). Separate visual pathways for perception and action. Trends in Neurosciences, 15, 20-25.

Goodale, M. A., Milner, A. D., Jakobson, L. P., \& Carey, D. P. (1991). A neurological dissociation between perceiving objects and grasping them. Nature, 349, 154-156.

Goodale, M. A., Pélisson, D., \& Prablanc, C. (1986). Large adjustments in visually guided reaching do not depend on vision of the hand or perception of target displacement. Nature, 320, 748-750.

Hansen, R. (1979). Spatial localization during pursuit eye movements. Vision Research, 19, 1213-1221.

Hansen, R., \& Skavenski, A. (1977). Accuracy of eye position information for motor control. Vision Research, 17, 919-926.

Hogan, N. (1985). The mechanics of multi-joint posture and movement control. Biological Cybernetics, 52, 315-331.

Hogan, N. (1990). Mechanical impedance of single- and multiarticular systems. In J. M. Winters \& S. L.-Y. Woo (Eds.), Multiple muscle systems: Biomechanics and movement organization (pp. 149-164). New York: Springer-Verlag.

Johansson, G. (1973). Monocular movement parallax and near space perception. Perception, 2, 135-146.

Kay, B. A., Hogan, N., Mussa-Ivaldi, F. A., \& Fasse, E. D. (1989). Perceived properties of objects using kinesthetic sense depend on workspace location. Society for Neuroscience Abstracts, 15 , 173.

Koenderink, J. J., \& van Doorn, A. J. (1978). How an ambulant observer can construct a model of the environment from the geometrical structure of the visual inflow. In G. Hauske \& E. Butenandt (Eds.), Kybernetik (pp. 224-247). Munich, Germany: Oldenburg.

Kugler, P. N., \& Turvey, M. T. (1987). Information, natural law, and the self-assembly of rhythmic movement. Hillsdale, NJ: Erlbaum.

Lederman, S. J., \& Klatzky, R. L. (1987). Hand movements: A window into haptic object recognition. Cognitive Psychology. $19,342-368$.

Lederman, S. J., \& Klatzky, R. (1990). Haptic exploration and object representation. In M. A. Goodale (Ed.), Vision and action: The control of grasping (pp. 98-109). Norwood, NJ: Ablex.

Lee, D. N. (1974). Visual information during locomotion. In R. B. McLeod \& H. L. Pick (Eds.), Perception: Essays in honor of James J. Gibson (pp. 250-260). Ithaca, NY: Cornell University Press. 
Lee, D. N. (1980). The optic flow field: The foundation of vision. Philosophical Transactions of the Royal Society of London, Series B, 290, 169-179.

Lee, D. N., \& Lishman, J. R. (1975). Visual proprioceptive control of stance. Journal of Human Movement Studies, 1, 87-95.

Loomis, J. M., Da Silva, J. A., Fujita, N., \& Fukusima, S. (1992). Visual space perception and visually directed action. Journal of Experimental Psychology: Human Perception and Performance, 18, 906-921.

Mack, A., Fendrich, R., \& Pleune, J. (1978). Adaptation to an altered relation between retinal image displacement and saccadic eye movements. Vision Research, 18, 1321-1327.

Marteniuk, R. G. (1978). The role of eye and head positions in slow movement execution. In G. E. Stelmach (Ed.), Information processing in motor learning and control (pp. 267-288). New York: Academic Press.

McMahon, T. A. (1984). Muscles, reflexes and locomotion. Princeton, NJ: Princeton University Press.

Milner, A. D., \& Goodale, M. A. (1993). Visual pathways to perception and action. Progress in Brain Research, 95, 317-337.

Milner, A. D., \& Goodale, M. A. (1995). The visual brain in action. Oxford, England: Oxford University Press.

Mussa-Ivaldi, F. A., Hogan, N., \& Bizzi, E. (1985). Neural, mechanical, and geometric factors subserving arm posture. Jourmal of Neuroscience, 5, 2732-2743.

Nakayama, K., \& Loomis, J. M. (1974). Optical velocity patterns, velocity sensitive neurons and space perception: A hypothesis. Perception, 3, 63-80.

Pagano, C. C., Fitzpatrick, P., \& Turvey, M. T. (1993). Tensorial basis to the constancy of perceived object extent over variations in dynamic touch. Perception \& Psychophysics, 54, 43-54.

Pagano, C. C., \& Turvey, M. T. (1995). The inertia tensor as a basis for the perception of limb orientation. Journal of Experimental Psychology: Human Perception and Performance, 21, 10701087.

Paillard, J., Michel, F., \& Stelmach, G. (1983). Localization without content: A tactile analogue of "blind sight." Archives of Neurology, 40, 548-551.

Pedhazur, E. (1982). Multiple regression in behavioral research. New York: Holt, Rinehart \& Winston.

Pélisson, D., Prablanc, C., Goodale, M. A., \& Jeannerod, M. (1986). Visual control of reaching movements without vision of the limb: II. Evidence of fast unconscious processes correcting the trajectory of the hand to the final position of a double-step stimulus. Experimental Brain Research, 62, 303-311.

Poulton, E. C. (1989). Bias in quantifying judgments. Hillsdale, NJ: Ertbaum.

Prablanc, C., Echallier, J. F., Jeannerod, M., \& Komilis, E. (1979). Optimal response of eye and hand motor systems in pointing at a visual target: II. Static and dynamic visual cues in the control of hand movement. Biological Cybernetics, 35, 183-187.

Prablanc, C., Echallier, J. F., Komilis, E., \& Jeannerod, M. (1979). Optimal response of eye and hand motor systems in pointing at a visual target: I. Spatio-temporal characteristics of eye and hand movements and their relationships when varying the amount of visual information. Biological Cybernetics, 35, 113-124.

Proffitt, D. R., Bhalla, M., Gossweiler, R., \& Midgett, J. (1995). Perceiving geographical slant. Psychonomic Bulletin and Review, 2, $409-428$.

Raibert, M. H. (1982). Legged robots that balance. Cambridge, MA: MIT Press.

Riccio, G. E. (1993). Information in movement variability about the qualitative dynamics of posture and orientation. In K. M.
Newell \& D. M. Corcos (Eds.), Variability and motor control (pp. 317-357). Champaign, IL: Human Kinetics.

Rieser, J. J., Ashmead, D. H., Taylor, C., \& Youngquist, G. (1990). Visual perception and the guidance of locomotion without vision to previously seen targets. Perception, 19, 675-689.

Rieser, J. J., Pick, H. L., Ashmead, D. H., \& Garing, A. E. (1995). Calibration of human locomotion and models of perceptualmotor organization. Journal of Experimental Psychology: Human Perception and Performance, 21, 480-497.

Rogers, B. J. (1993). Motion parallax and other dynamic cues for depth in humans. In R. A. Miles \& J. Wallman (Eds.), Visual motion and its role in the stabilization of gaze (pp. 119-137). Amsterdam: Elsevier.

Rossetti, Y., Rode, G., \& Boisson, D. (1995). Implicit processing of somaesthetic information: $A$ dissociation between where and how? NeuroReport, 6, 506-510.

Runeson, S., \& Frykholm, G. (1981). Visual perception of lifted weight. Journal of Experimental Psychology: Human Perception and Performance, 7, 733-740.

Saltzman, E., \& Kelso, J. A. S. (1987). Skilled actions: A task-dynamic approach. Psychological Review, 94, 84-106.

Schneider, G. E. (1969). Two visual systems. Science, 163, 895-902.

Solomon, H. Y. (1988). Movement-produced invariants in haptic explorations: An example of a self-organizing, informationdriven, intentional system. Human Movement Science, 7, 201224.

Solomon, H. Y., \& Turvey, M. T. (1988). Haptically perceiving the distances reachable with hand-held objects. Journal of Experimental Psychology: Human Perception and Performance, 14, 404-427.

Trevarthen, C. B. (1968). Two mechanisms of vision in primates. Psychologische Forschung, 31, 299-337.

Turvey, M. T. (1977). Preliminaries to a theory of action with reference to vision. In R. J. Shaw \& J. Bransford (Eds.), Perceiving, acting, and knowing: Toward an ecological psychology (pp. 211-265). Hillsdale, NJ: Erlbaum.

Turvey, M. T., \& Carello, C. (1995). Dynamic touch. In W. Epstein \& S. Rogers (Eds.), Handbook of perception and cognition: Vol. 5. Perception of space and motion (pp. 401-490). New York: Academic Press.

Ungerleider, L. G., \& Mishkin, M. (1982). Two cortical visual systems. In D. J. Ingle, M. A. Goodale, \& J. W. Mansfield (Eds.), Analysis of visual behavior (pp. 549-586). Cambridge, MA: MIT Press.

Warren, W. H., \& Hannon, D. J. (1990). Eye movements and optical flow. Journal of the Optical Society of America, Series A, $7,160-169$.

Warren, W. H., Mestre, D. R., Blackwell, A. W., \& Morris, M. W. (1991). Perception of circular heading from optical flow. Journal of Experimental Psychology: Human Perception and Performance, $21,28-43$.

Warren, W. H., Morris, M. W., \& Kalish, M. (1988). Perception of translation heading from optical flow. Joumal of Experimental Psychology: Human Perception and Performance, 21, 646660.

Wong, E., \& Mack, A. (1981). Saccadic programming and perceived location. Acta Psychologica, 48, 123-131.

Worringham, C. J. (1991). Variability effects on the internal structure of rapid aiming movements. Journal of Motor Behavior, $23,75-85$.

Worringham, C. J. (1993). Predicting motor performance from variability measures. In K. M. Newell \& D. M. Corcos (Eds.), Variability and motor control (pp. 117-156). Champaign, IL: Human Kinetics. 
Appendix A

Actual Target Distances (in Centimeters) as a Function of the Proportion of Maximum Reach for Each of the 4 Participants

\begin{tabular}{ccccccccccccc}
\hline & Maximum & \multicolumn{10}{c}{ Proportion of maximum reach } \\
\cline { 2 - 11 } Participant & reach & $\mathbf{0 . 5 0}$ & 0.58 & $\mathbf{0 . 6 6}$ & 0.70 & 0.76 & $\mathbf{0 . 8 1}$ & $\mathbf{0 . 8 6}$ & $\mathbf{0 . 9 2}$ & 1.06 & 1.20 \\
\hline 1 & 69.7 & 34.8 & 40.4 & 46.0 & 48.8 & 53.0 & 56.5 & 59.9 & 64.1 & 73.9 & 83.6 \\
2 & 65.7 & 32.8 & 38.1 & 43.4 & 46.0 & 49.9 & 53.2 & 56.5 & 60.4 & 69.6 & 78.8 \\
3 & 54.7 & 27.4 & 31.7 & 36.1 & 38.3 & 41.6 & 44.3 & 47.0 & 50.3 & 58.0 & 65.6 \\
4 & 54.7 & 27.4 & 31.7 & 36.1 & 38.3 & 41.6 & 44.3 & 47.0 & 50.3 & 58.0 & 65.6 \\
\hline
\end{tabular}

\section{Appendix B}

\section{Acronym Structure}

\section{Definition of Acronym Terms}

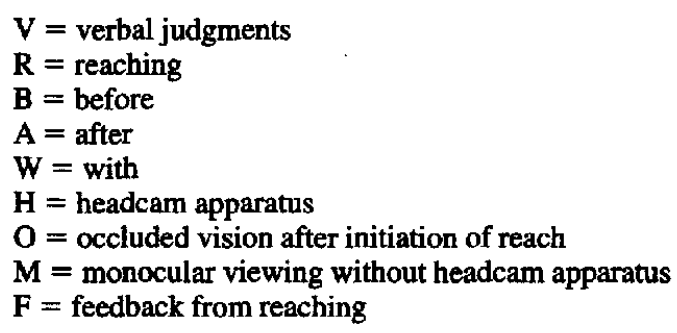

\section{Acronym for Each Condition in Order of Presentation}

VBR = verbal judgment condition performed before any reaching conditions.

RH = reaching with vision through the headcam (referred to as "headcam reach" by Bingham \& Pagano, 1998).

ROH = reaching with vision through the headcam available only before reach initiation (referred to as "ballistic headcam reach" by Bingham \& Pagano, 1998).

RM = monocular reaching without the headcam (referred to as "monocular reach" by Bingham \& Pagano, 1998).

VAR = verbal judgment condition performed after above reaching conditions.

VWR/RWV = verbal judgments and reaches, respectively, performed together (with a verbal judgment immediately preceding a reach).

VAF = verbal judgment condition performed after the feedback from reaching available in the VWR/RWV condition.

Received August 20, 1996 